\title{
Platelet autologous plasma in post-traumatic knee osteoarthritis treatment
}

\author{
Halyna Havryliuk*, Liudmyla Khimion \\ Family Medicine Department of Shupyk National Medical Academy of Postgraduate Education, Kiev, Ukraine
}

\section{A R T I C L E I N F O}

\section{Article history:}

Received 25 April 2018

Received in revised form

27 July 2018

Accepted 2 August 2018

Available online 6 August 2018

\section{Introduction}

Osteoarthritis (OA) is the most common chronic joint disease, which has detrimental effects on the patients quality of life and functional status. Overtime, the continuing progression of the pathological process leads to involvement in inflammation and degradation all structural components of the joint - capsule, ligaments, synovial membrane and periarticular muscles. The main cause for the disease progression is development of disbalance between the articular cartilage repairment and injury due to mechanical loading, every day damage and shift of the balance to the catabolic processes.

The weight of OA in the general structure of the diseases is $12 \%,{ }^{8}$ with the most commonly affected knees, hips and hands joints. The prevalence of $\mathrm{OA}$ depends on age and sex (increasing with age, slightly more prevalent among women); also it's worth mentioning that epidemiologic data about OA is significantly influenced by the geographic area of study and methods used for OA diagnostic visualization. $\mathrm{X}$ ray methods of $\mathrm{OA}$ visualization are the most reliable for the disease prevalence determination. Among all joints the knee is the most frequently affected joint (Fig. 1). ${ }^{4}$

According to classification there are two main pathogenetic variants of OA: primary (idiopathic) and secondary, which develops as a consequence of trauma and other damaging factors. Idiopathic $\mathrm{OA}$ is mostly the disease of elderly with prevalence of the disease $50 \%-97 \%$ in ages between 65 and 75 years respectively; but secondary OA can develop in any age group and diagnosed in

\footnotetext{
* Corresponding author. 9 Dorogozhytska str, 04112, Kyiv, Ukraine.

E-mail address: fmdnmacademy@gmail.com (H. Havryliuk).
}

approximately $14 \%$ of patients under the age of 25 . $^{7}$

One of the most common cause of secondary knee OA in young patients is trauma which leads to the preliminary cartilage degradation and development of symptomatic disease in the first 3-5 years after trauma.

Recent studies have shown that the action of the joint to the injury is systemic, and not just an isolated cartilage reaction. The main mechanisms of the development of post-traumatic OA include apoptosis of articular chondrocytes and activation of the inflammatory cascade in the joint, which leads to degenerative changes in the cartilage.

The initial injury results in acute tissue damage with the release of matrix molecules into the extracellular space, which prompting a robust release of pro-inflammatory (IL-1, IL-6, Il-8, TNFa, chemokines) and anti-inflammatory mediators (IL-10,IL-1RA) in the first $48 \mathrm{~h}$ after injury. Further inflammatory changes in the joint have determined stages and terms of development. ${ }^{3}$

After the acute post-trauma phase, cytokines concentration generally decreases but levels of IL-6, IL-8, and IL-1Ra are elevated in the first week after injury. During the subacute period (from 1 week to 2 months), IL-6 level remains elevated, together with other cytokines and chemokines. In chronic phase (from 2 months to $>1$ year), the IL-6 and IL- 8 are elevated, but IL-1Ra often falls lower than normal. Level of TNF $\alpha$ is increasing in subacute phase and persists the same level in the chronic phase (after 1 year after the injury). It is important to note that the pro-inflammatory response in some patients does not get adequate controlling time after injury, there by chronic inflammation and tissue damage progresses further, leading to PTOA. ${ }^{1}$ Progressive synovial inflammation builds the background for the changes in synovial fluid chemical composition, which, in combination with intensive 

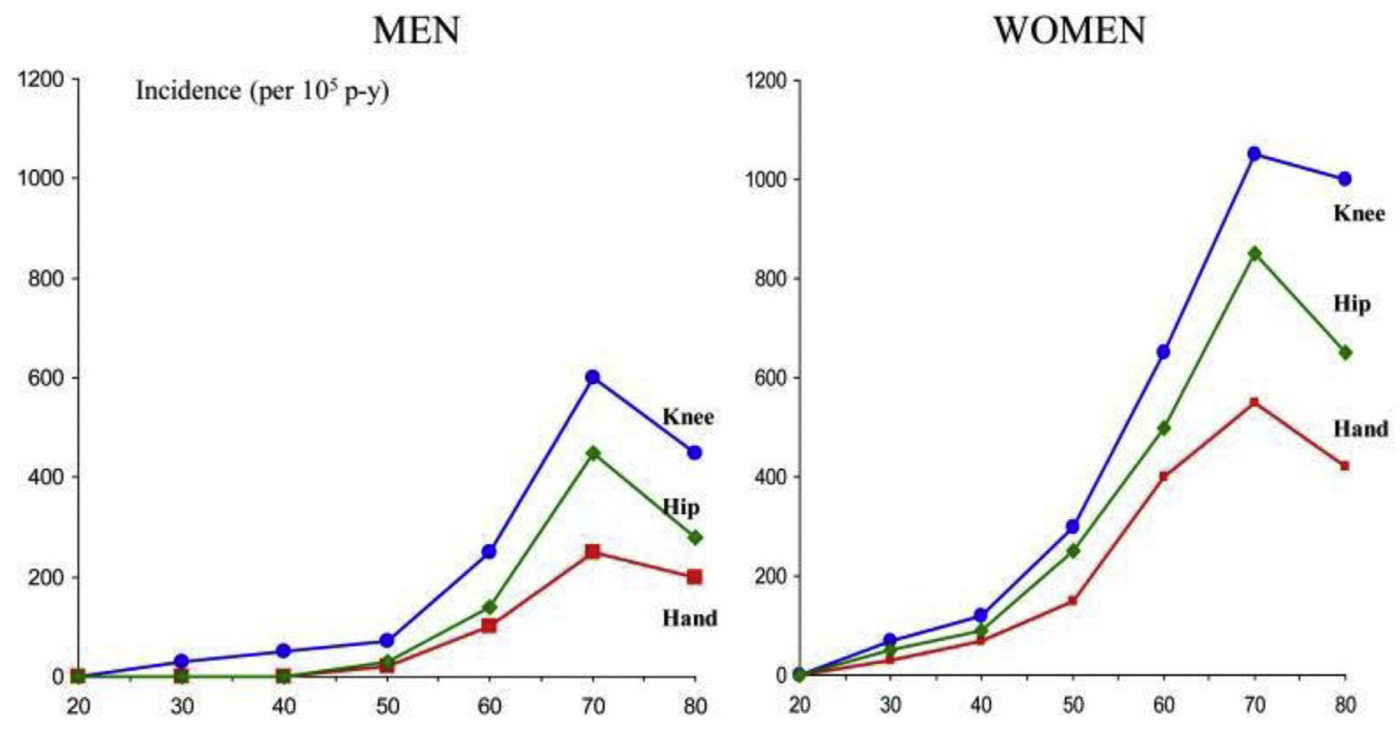

Age (yrs)

Fig. 1. Incidence of symptomatic osteoarthritis fallon health plan (4).

release of the proinflammatory cytokines, causes the development of the wide range secondary alterations. Over time, articular cartilage thinning and becomes less elastic, the articular surfaces of the bones lose resilience properties, become polished and sealed, which leads to the development of the subchondral osteosclerosis. Further inflammatory involvement of the articular capsule, subchondral bones, ligaments and muscles as well as deformation of the joint leads to a continuous progressive course of the disease. ${ }^{5}$

According to the Osteoarthritis Research Society International (OARSI) and the American Academy of Orthopaedic Surgeons (AAOS) recommendations, the standard of OA treatment consists of non-pharmacological interventions, pharmacologic treatment and surgery (Treatment of Osteoarthritis of the Knee. 2nd edn. Rosemont: American Academy of Orthopaedic Surgeons, 2013). Nonpharmacological interventions include body weight control, regular moderate physical activity, life style changes, use of multimodal therapy and orthopaedic devices. In case of knee OA the treatment program includes physical therapy, fitness walking and aerobic exercises and training, which evidenced to improve joint function in $\mathrm{OA}^{2}$ Pharmacologic treatment aims mainly to keep pain and inflammation under control but can't reverse the cartilage damage. Surgery is only considered for severe cases when other treatment is ineffective. Unfortunately, arthroplasty is not recommended for young patients (usually the artificial implant has a lifespan limits in $15-20$ years). ${ }^{6}$

The unsatisfactory final results and unacceptable side effects associated with standard OA treatment warrant the continued search for potential new therapy. At present the regenerative methods which use different kinds of blood, mesenchymal and bone marrow derived compounds are rather widely investigated for OA treatment. Among the mentioned methods the easiest in performing is use of autologous patient plasma with different number of platelets (platelet rich plasma, platelet normal plasma). Autologous platelet plasma demonstrated anti-inflammatory and regenerative effects in experiment and clinical practice which makes it promising for OA treatment.

\section{Objective}

To investigate clinical efficacy and safety of platelet autologous plasma (PAP) comparing to standard treatment in young patients with symptomatic post-traumatic knee $\mathrm{OA}$ and in early period of the knee injury.

\section{Materials and methods}

The prospective comparative study was conducted at the Department of Family Medicine of the Shupyk National Medical Academy of Postgraduate Education based on Kiev Regional Clinical Hospital and approved by Academy Ethics Committee. Our study included 122 patients (mean age $34.81 \pm 4.28$ years): 62 - with established symptomatic post-traumatic knee OA (PTOA) (mean time from trauma $-46.87 \pm 2.09$ months), I-Il stage (X-ray) and 60 - in early period after intra-articular knee trauma (KT) (confirmed by MRI, $20.15 \pm 1.72$ days after injury). The patients after knee surgery, with inflammatory arthritis or any other uncontrolled diseases and disorders were not included in the study. All patients signed the informed consent forms to participate in study.

Table 1

Main demographic and clinical characteristics of patients enrolled into the study.

\begin{tabular}{|c|c|c|c|c|}
\hline \multirow[t]{2}{*}{ Parameter } & \multicolumn{2}{|l|}{ KT group, $\mathrm{n}=60$} & \multicolumn{2}{|c|}{ PTOA group, $n=62$} \\
\hline & Group $1 \mathrm{~N}=30$ & Group $2 \mathrm{~N}=30$ & Group $1 \mathrm{~N}=30$ & Group $2 \mathrm{~N}=32$ \\
\hline Mean age, years & $31.83 \pm 2.41$ & $31.97 \pm 2.58$ & $37.17 \pm 3.91$ & $38.26 \pm 3.41$ \\
\hline Women & 13 & 11 & 16 & 17 \\
\hline Men & 17 & 19 & 14 & 15 \\
\hline Time from trauma, days/months & $20.23 \pm 1.92$ & $20.06 \pm 1.48$ & $46.9 \pm 1.9$ & $46.83 \pm 2.29$ \\
\hline
\end{tabular}

NOTE: PTOA: post-traumatic osteoarthritis. KT: knee trauma. 
Table 2

Dynamic changes in KOOS and VAS Score in patients with PTOA.

\begin{tabular}{|c|c|c|c|c|c|c|c|c|c|c|}
\hline \multirow[t]{3}{*}{ Parameter } & \multicolumn{2}{|c|}{ Before treatment } & \multicolumn{4}{|c|}{ Early observational period } & \multicolumn{4}{|c|}{ Late observational period } \\
\hline & \multirow[b]{2}{*}{ Gr.1 } & \multirow[b]{2}{*}{ Gr.2 } & \multicolumn{2}{|l|}{ After 2 weeks } & \multicolumn{2}{|l|}{ After 4 weeks } & \multicolumn{2}{|c|}{ After 6 months } & \multicolumn{2}{|c|}{ After 12 months } \\
\hline & & & Gr.1 & Gr.2 & Gr.1 & Gr.2 & Gr.1 & Gr.2 & Gr.1 & Gr.2 \\
\hline $\begin{array}{l}\text { KOOS: } \\
\text { - Pain } \\
\text { - Symptoms } \\
\text { - Affect daily life } \\
\text { - Sport and Recreation } \\
\text { - Quality of Life } \\
\text { VAS }\end{array}$ & $\begin{array}{l}48.61 \pm 6.46 \\
45.75 \pm 11.23 \\
55.79 \pm 5.39 \\
14.22 \pm 6.74 \\
23.83 \pm 8.01 \\
46.31 \pm 2.89 \\
\end{array}$ & $\begin{array}{l}47.22 \pm 6.3 \\
45.27 \pm 12.3 \\
56.21 \pm 5.87 \\
13.68 \pm 8.01 \\
23.9 \pm 6.96 \\
45.64 \pm 2.76 \\
\end{array}$ & $\begin{array}{l}63.58 \pm 6.44 \\
57.33 \pm 8.62 \\
62.08 \pm 3.91 \\
31.17 \pm 5.52 \\
45.21 \pm 7.99 \\
31.14 \pm 1.74 \\
\end{array}$ & $\begin{array}{l}67.36 \pm 7.89^{*} \\
59.37 \pm 5.03 \\
70.22 \pm 4.75^{*} \\
35.16 \pm 5.16^{*} \\
50.2 \pm 7.69^{*} \\
26.31 \pm 1.35^{*} \\
\end{array}$ & $\begin{array}{l}69.26 \pm 4.19 \\
64.29 \pm 9.47 \\
69.02 \pm 3.45 \\
34.33 \pm 5.04 \\
48.33 \pm 7.14 \\
22.15 \pm 2.03 \\
\end{array}$ & $\begin{array}{l}77.52 \pm 5.48^{*} \\
69.64 \pm 5.29^{*} \\
74.36 \pm 4.4^{*} \\
41.72 \pm 6.91^{*} \\
56.64 \pm 10.16^{*} \\
15.97 \pm 1.26^{*} \\
\end{array}$ & $\begin{array}{l}52.32 \pm 5.75 \\
51.31 \pm 5.82 \\
60.78 \pm 3.03 \\
27.17 \pm 6.39 \\
38.13 \pm 6.84 \\
35.42 \pm 1.92 \\
\end{array}$ & $\begin{array}{l}76.04 \pm 4.51^{*} \\
70.2 \pm 5.34^{*} \\
79.37 \pm 4.55^{*} \\
54.2 \pm 4.23^{*} \\
61.52 \pm 7.79^{*} \\
19.33 \pm 2.24^{*} \\
\end{array}$ & $\begin{array}{l}49.17 \pm 5.01 \\
48.57 \pm 5.75 \\
61.31 \pm 3.08 \\
17.17 \pm 5.03 \\
27.83 \pm 7.88 \\
37.33 \pm 2.13 \\
\end{array}$ & $\begin{array}{l}76.82 \pm 5.85^{*} \\
74.44 \pm 3.86^{*} \\
77.53 \pm 3.13^{*} \\
55.78 \pm 4.77^{*} \\
72.85 \pm 4.66^{*} \\
12.11 \pm 2.53^{*} \\
\end{array}$ \\
\hline
\end{tabular}

NOTE. KOOS Score: Knee injury and Osteoarthritis Outcome Score. VAS Score: Visual Analog Score for pain. PTOA: post-traumatic osteoarthritis.

*significant difference between Gr.1 and Gr.2, p $<0.05$.

Patients with established PTOA and knee trauma (KT) were divided in 2 groups - first group received standard treatment (NSAIDs, exercises, complex physiotherapy for patients with PTOA and NSAIDs, complex physiotherapy for patients with KT), second -in addition to the standard treatment received course of 3 intraarticular injections of PAP. The demographic characteristics of enrolled patients are given in Table 1.

PAP was prepared by standard method from patient venous blood using special blood collection tubes with gel; tubes with $9 \mathrm{ml}$ of the whole blood then have been centrifuged ( $3000 \mathrm{rpm}$ for 5 min at a $65-75^{\circ}$ angle) to separate the platelet plasma suspension from the components of the blood), obtained PAP $(3-5 \mathrm{ml})$ was then injected into affected knee. Mean platelet concentration in PAP was $\left(280-320 \pm 22.1 \times 10^{6}\right) / \mathrm{mL}$. Course of PAP treatment consisted of 3 injections with $4( \pm 1)$ day intervals between. Efficacy of treatment in both groups was evaluated by standard recommended scales (KOOS questionnaire (Knee injury and Osteoarthritis Outcome Score) and VAS pain score (Visual Analog Scale). Also all enrolled patients underwent standard complex evaluation prior to the treatment (general clinical and joint examination, knee $\mathrm{X}$-ray/MRI; laboratory tests included hematology, ESR and plasma hpCRP level). Complex of clinical and laboratory examinations, questionnaires assessment was repeated in 2 and 4 weeks, 6 and 12 months after course of treatment.

All study data were imported and analyzed by SPSS v.21. For comparing variables with normal distribution, ANOVAs test was used. Qualitative variables were shown as frequency and percent. For evaluating the relationship between quantitative variables, correlation coefficients of Pearson and Sperman were used.

\section{Results}

During early observation period (first 4 weeks) all patients from
PTOA group demonstrated improvement in pain and functional activity as it is shown in Table 2, in 2 weeks of active treatment of OA exacerbation patients of both subgroups showed significant improvement in pain, symptoms and quality of life comparing to baseline values but patients from Gr.2 also had less affected daily living activities and better points in sport and recreation subscale. In 4 weeks the difference between subgroups were more prominent, with better results of treatment in subgroup treated with PAP. Later, during the late observation period second subgroup still demonstrated better outcomes (both comparing to the baseline and to the first subgroup); at that period of study one third of patients from Gr.1 experienced 1-2 OA exacerbations, in Gr.2 only $6.45 \%$ of patient had had 1 OA exacerbation $(\mathrm{p}<0.05)$. By the end of the 12 months the majority of Gr.2 patients still had better knee functions and less pain comparing to the baseline, while Gr.1 patients showed no significant difference in all KOOS parameters. The same dynamics of the investigated parameters were also observed during treatment of patients in early period of knee trauma (Table 3).

No significant complications were observed during PAP use, except for temporary local pain at the injection site.

\section{Conclusion}

Use of PAP intraarticular injections in complex treatment of symptomatic knee OA and in early phase after knee trauma helps to improve both early and late results of treatment, decreases the number of symptoms exacerbations during 12 months after treatment.

\section{Discussion}

The application of PRP to the treatment was developed because

Table 3

Dynamic changes in KOOS and VAS Score in patients with KT.

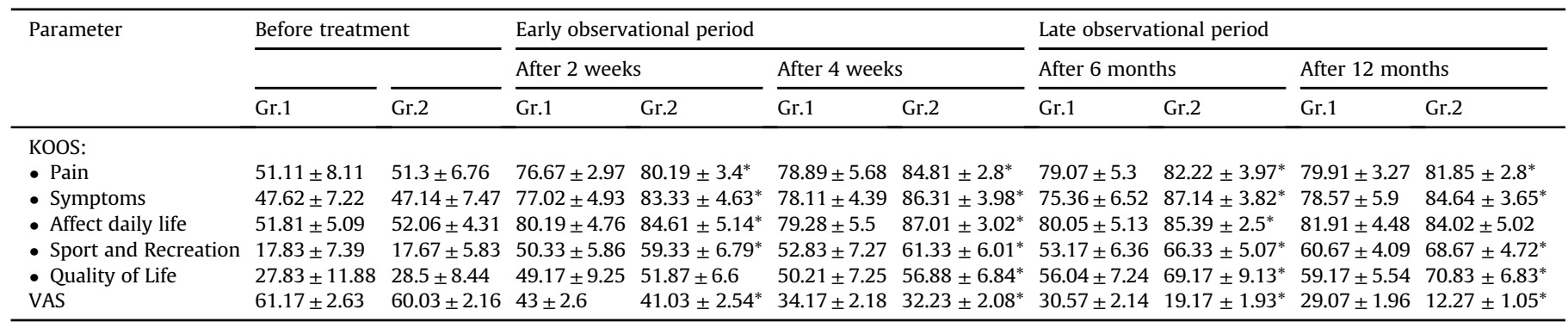

NOTE. KOOS Score: Knee injury and Osteoarthritis Outcome Score. VAS Score: Visual Analog Score for pain. KT: knee trauma.

*- significant difference between Gr.1 and Gr.2, p < 0.05 . 
of the roles of growth factors expressed in platelets, which lead to tissue regeneration. Intra-articular PRP injection was reported to be effective in degenerative knees in several studies.

This study showed that PAP intra-articular injections in complex treatment PTOA comparing to standard treatment leads to clinical improvements in pain and knee functionality during 12 months. Moreover the evidence shows that the use of PRP has similar effects patients with knee trauma. Our study showed PRP did not increase the risk of adverse events compared with standard treatment.

However, we believe efficacy of treatment intra-articular PRP injection should be evaluated in a longer period of time. Consequently the new clinical studies should do be oriented to analyze a longer treatment or observational period.

A more effective therapy for knee OA can delay of some years arthroplasty and this delay could lead to reduce the total OA economic impact on Healthcare Systems.

\section{Sources of funding}

This research did not receive any specific grant from funding agencies in the public, commercial, or not-for-profit sectors.

\section{Conflicts of interest}

The author below certify that he have NO affiliations with or involvement in any organization or entity with any financial interest (such as honoraria; educational grants; participation in speakers' bureaus; membership, employment, consultancies, stock ownership, or other equity interest; and expert testimony or patent-licensing arrangements), or non-financial interest (such as personal or professional relationships, affiliations, knowledge or beliefs) in the subject matter or materials discussed in this manuscript.

\section{Appendix A. Supplementary data}

Supplementary data related to this article can be found at https://doi.org/10.1016/j.jcot.2018.08.007.

\section{References}

1. Harkey MS, Luc BA, Golightly YM, et al. Osteoarthritis-related biomarkers following anterior cruciate ligament injury and reconstruction: a systematic review. Osteoarthritis Cartilage. 2015;23:1-12.

2. Kon E, Filardo G, Drobnic M, et al. Non-surgical management of early knee osteoarthritis. Knee Surg Sports Traumatol Arthrosc. 2012;20, 436-9.

3. Lieberthal J, Sambamurthy N, Scanzello CR. Inflammation in joint injury and post-traumatic osteoarthritis. Osteoarthritis Cartilage. 2015 Nov;23(11): 1825-1834.

4. Litwic A, Edwards M, Dennison E, Cooper C. Epidemiology and burden of osteoarthritis. Br Med Bull. 2013;105:185-199.

5. Scanzello CR, Goldring SR. The role Synovitis in Osteoarthritis pathogenesis. Bone. 2012;51:249-257.

6. Zhang Wei, Ouyang Hongwei, Dass Crispin R, Xu Jiake. Current research on pharmacologic and regenerative therapies for osteoarthritis. Bone Res. 2016;4. Article number: 15040.

7. ИЛ Давидкіна, ЮВ Щукіна. Поліклінічна ТераШія : Підручник. М. ГЕОТАР-Медія; 2013:688c.

8. ГГ Голки, ОА Бурьянова, ВГ Климовицького. Травматологія Та ОртоШедія: Підручник Для студ. вищих мед. навч. закладів. Вінниця: Нова Книга. 2014, 416 с. 